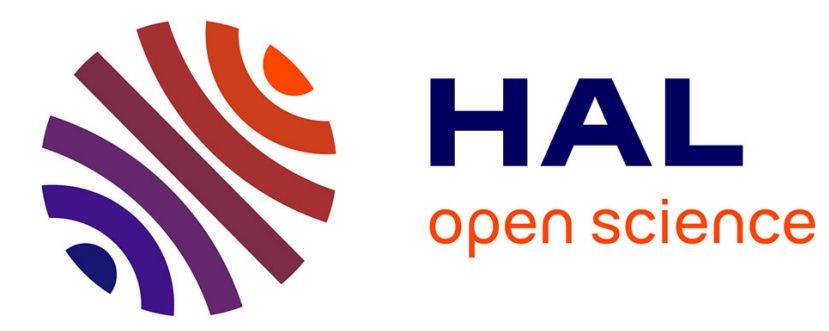

\title{
Configurational Stability of Chlorophosphines
}

Stéphane Humbel, Cyrille Bertrand, Christophe Darcel, Christophe Bauduin, Sylvain Jugé

\section{To cite this version:}

Stéphane Humbel, Cyrille Bertrand, Christophe Darcel, Christophe Bauduin, Sylvain Jugé. Configurational Stability of Chlorophosphines. Inorganic Chemistry, 2003, 42, pp.420 - 427. $10.1021 /$ ic026128u . hal-01564785

\section{HAL Id: hal-01564785 \\ https://hal.science/hal-01564785}

Submitted on 19 Jul 2017

HAL is a multi-disciplinary open access archive for the deposit and dissemination of scientific research documents, whether they are published or not. The documents may come from teaching and research institutions in France or abroad, or from public or private research centers.
L'archive ouverte pluridisciplinaire HAL, est destinée au dépôt et à la diffusion de documents scientifiques de niveau recherche, publiés ou non, émanant des établissements d'enseignement et de recherche français ou étrangers, des laboratoires publics ou privés. 


\title{
On the Configurational Stability of
}

\section{Chlorophosphines}

\author{
Stéphane Humbel ${ }^{* a}$ and Cyrille Bertrand ${ }^{a}$, \\ Christophe Darcel, ${ }^{b}$ Christophe Bauduinc and Sylvain Jugé*b
}

a Groupe Modélisation \& Réactivité Chimique, UMR 6519, Université de Reims,

Moulin de la Housse, BP 1039, 51687 Reims Cedex 2, France; stephane.humbel@univ-reims.fr

b Laboratoire de Synthèse et d' Electrosynthèse Organométalliques, UMR 5632, Université de Bourgogne, 6 Bd Gabriel, BP 138, 21100 Dijon, France; Sylvain.Juge@ u-Bourgogne.fr c Université de Cergy Pontoise, 5 mail Gay Lussac, 95031 Cergy Pontoise Cedex, France

\section{Abstract}

The configurational stability of chlorophosphines is investigated. Several mechanisms involving chlorophosphine monomer, dimers and adducts with $\mathrm{HCl}$ are evaluated by Density Functional Theory calculations. The presence of $\mathrm{HCl}$ in the medium is found to catalyze the P-center chiral inversion at room temperature. The reaction involves a two-step mechanism with low transition states $\left(10 \mathrm{kcal} . \mathrm{mol}^{-1}\right)$ and a stabilized achiral intermediate $\left(-2.6 \mathrm{kcal} . \mathrm{mol}^{-}\right.$ 
$\left.{ }^{1}\right)$. Further calculations and experiments on the halogen exchange with HBr corroborate this mechanism, with bromophosphines being formed instantaneously.

\section{Introduction}

During the last three decades, there has been considerable development in asymmetric transition metal catalyzed reactions, ${ }^{1}$ especially in the area of chiral ligands, ${ }^{2}$ where chiral P(III)-organophosphorus derivatives (diphosphines, ${ }^{3}$ diphosphinites, ${ }^{4}$ aminophosphine-phosphinites, ${ }^{5}$ chelating monophosphines ${ }^{6}$ ) have been widely used. The synthesis of these ligands is usually performed using achiral chlorophosphines $\mathbf{1}$ (Scheme $1, \mathrm{R}^{1}=\mathrm{R}^{2}$ ), either as electrophilic ${ }^{7}$ (Scheme 1a) or nucleophilic reagents, ${ }^{8}$ in the latter case, through the formation of phosphides (Scheme 1b).

Scheme 1

It is interesting to note that the most commonly used P(III) organophosphorus ligands generally bear the chirality on the carbon backbone. If enantiomerically enriched chlorophosphines $\mathbf{1}$ (Scheme $1, \mathrm{R}^{1} \neq \mathrm{R}^{2}$ ) were available, they could be useful building blocks for the synthesis of a new class of bulky, hybrid or functionalized P-chirogenic ligands, which would bring the chiral center close to the metal.

Previous studies on the pyramidal inversion of chlorophosphines indicate that they are configurationally stable, with even higher energy barriers than tertiary phosphines, 40.0 and $35.6 \mathrm{kcal}^{\mathrm{mol}}{ }^{-1}$, respectively. ${ }^{9}$ It is 
well established that this increased barrier in chlorophosphines originates from both the $\sigma$ attracting and the $\pi$ donating abilities of the chlorine substituent. Both favor the pyramidalization of the phosphorus and hence increase the monomeric inversion barrier. $9 \mathrm{~b}, 10$

However, only the partially enantiomerically enriched $t$ butylchlorophenylphosphine $\mathbf{1 d}$ has been described to date.11,12 This compound, which was obtained by a phosphonium salt decomposition at low temperature (Scheme 2a), or by kinetic resolution, slowly racemized at room temperature. The pioneering work of Horner and Jordan ${ }^{13}$ described the formation of a racemic chlorophosphine 1e from enantiomerically enriched ethylphenylaminophosphine (Scheme $2 \mathrm{~b}$ ). These authors postulated that the aminophosphine acidolysis with $\mathrm{HCl}$ was stereoselective and the resulting chlorophosphine 1e was believed to racemize by intermolecular ligand exchange through the dimeric species $\mathbf{2 e}$.

Scheme 2

To date, the origin of the racemization has not been clearly established and remains unclear. It might be due either to the acidolysis step conditions or to the inherent configurational instability of the chlorophosphines as postulated by Horner and Jordan. ${ }^{13}$ In order to clarify this point, we envisaged various racemization processes.

In the present contribution, we report the results of our investigation on the configurational stability of chlorophosphines and on the racemization 
mechanism with acids $(\mathrm{HCl}, \mathrm{HBr}) .{ }^{14}$ We describe herein experimental and computational studies on the halogen exchange between a chlorophosphine and $\mathrm{HBr}$.

\section{Computational details}

The calculations were carried out using a gas phase model with the Gaussian 98 package. ${ }^{15}$ Cartesian D orbitals were used throughout this study.

All geometry optimizations were done using the Density Functional Theory (DFT) approximation B3LYP.16 In a first stage, the geometries were optimized using the CEP-31G(D) basis set. The core electrons of the P, C1 and $\mathrm{Br}$ atoms were thus described with a "core" potential, while the other electrons were described with a double $\zeta$ basis set plus polarization function on the heavy atoms $\mathrm{P}, \mathrm{Cl}, \mathrm{Br}, \mathrm{C}$.

These geometries were then used as starting geometries for subsequent geometry optimizations using the "all-electron" basis set, B3LYP/6$31+\mathrm{G}(2 \mathrm{~d})$ level, which avoid the core potential and provides on the heavy atoms both diffuses functions and a double $\zeta$ quality of the gaussian basis. These reoptimizations led in fact to very small stabilizations of each structure, between 0.5 and $1.2 \mathrm{kcal} / \mathrm{mol}$. These converging results show the good quality of the optimization level. The stationary points were then characterized as minimum or Transition State (TS) by analytical frequency calculations. Corresponding unscaled Zero Point Correction (ZPC) and entropy are indicated in the tables. The energies obtained using this optimization level (B3LYP/6-31+G(2d)) are noted $\Delta \mathrm{H}^{\mathrm{Opt}}$ in the following. 
The energies were then calculated within the same B3LYP model, using the more extended basis set $6-311++G(2 d, p)$. In this paper, we mainly comment on the results from these "dual-level" calculations (noted, as usually, B3LYP/6-311++G(2d,p)//B3LYP/6-31+G(2D)). Those triple $\zeta$ calculations provide the data for what we called $\Delta \mathrm{H}^{\mathrm{TZ}}$. When $\Delta \mathrm{H}^{\mathrm{TZ}}$ is corrected for the $\mathrm{ZPC}$ it is noted in the following $\Delta \mathrm{H}^{\mathrm{TZ}} \mathrm{ZPC}$. Gas phase Gibbs free energies at room temperature $\Delta \mathrm{G}^{298}$, are also indicated in the tables.

\section{Results and discussion}

\section{Computational results}

The computational investigation was carried out using the chlorodimethylphosphine $\left(\mathbf{1} \mathbf{a}, \mathrm{R}^{1}=\mathrm{R}^{2}=\mathrm{Me}\right)$ as a model. While this species is not chiral, it was useful in studying the different racemization mechanisms under consideration. Since the racemization of P-chirogenic chlorophosphines must pass through at least one transition state (TS) or one intermediate bearing an achiral phosphorus center, we considered pathways involving such species. Consequently, we envisaged the species TS2a-5a as possible origins of this process. The monomeric planar transition state (TS) 3a, known as an impossible pathway for a room temperature chiral inversion (vide supra), is included here for the sake of completeness.

If we consider a mechanistic explanation involving two molecules of chlorodimethylphosphine 1a, two kinds of species (intermediate or transition state (TS)) can be hypothesized: the dimeric species $\mathbf{2 a}$, similar to $\mathbf{2 e}$ previously proposed by Horner, 13 with two chlorine atoms bridging the two 
phosphorus atoms, and the pentacoordinate phosphorane 4a. In this hypervalent species, a phosphorus-phosphorus bond is formed in the equatorial position, and the two chlorine atoms are in apical positions. Other stereoisomers with one or two chlorine atoms in the equatorial position were not investigated, due to the strong apicophilicity of this substituent. ${ }^{17}$ Finally, structure 5a results from the $\mathrm{HCl}$ addition to the chlorophosphine 1a. The formation of such a pentacoordinate phosphorus derivative could be considered under the acidolysis conditions of the aminophosphine precursor.

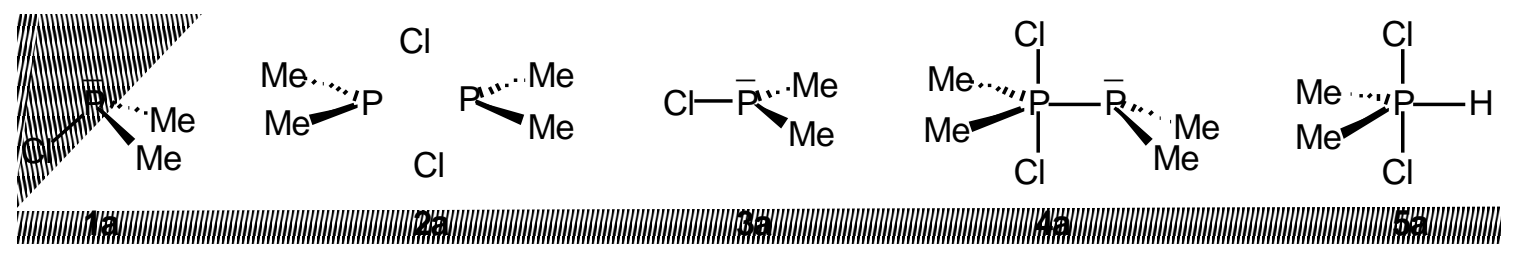

The optimized structures for the intermediates and transition states derived from 1a and their corresponding energies are reported in Figure 1 and Table 1, respectively. The transition state TS3a, resulting from an umbrella inversion, is found to be $51.6 \mathrm{kcal} . \mathrm{mol}^{-1}$ higher in energy than 1a (Table 1, entry 2). Not surprisingly, the energy barrier is much too high to consider a stereochemical path passing through this TS at room temperature. ${ }^{9,10}$

Figure $1 \&$ Table 1

The bimolecular species TS2a was characterized as a transition state rather than an intermediate (Figure 1). In this structure, one chlorine atom is bonded to both phosphorus atoms, while the other is further apart. The reaction coordinate, as indicated by the arrows, clearly shows the chlorine 
exchange between the phosphorus atoms. Thus, TS2a can indeed be involved in the racemization process. It corresponds to an intermolecular nucleophilic substitution at the phosphorus center. The top-view of TS2a shows the important distortion of the phosphorus substituents with two methyl groups in the plane of the square formed by the phosphorus and the chlorine atoms, and two others in the axial position. This distortion is attributed to the phosphorus-phosphorus lone pair repulsion (Scheme 3a). Because this repulsion can not be completely avoided, the energy of TS2a is high, 58.3 kcal.mol-1 above the energy of the starting chlorodimethylphosphine $\mathbf{1 a}$ (Table 1, entry 3 ). Since such high activation energy is clearly unattainable at room temperature, we rejected this pathway for the racemization.

A better mechanism, which would reduce the phosphorus-phosphorus lone pair repulsion, should consider the phosphorus atoms as both nucleophilic and electrophilic centers (biphilicity). ${ }^{18}$ In this case (Scheme $3 b)$, the lone pair of the phosphorus atom of one chlorodimethylphosphine $\mathbf{1 a}$ reacts to displace the chlorine of the other. This leads to the pentacoordinate intermediate $4 \mathbf{a}$ through the transition state TS4a. It can be pointed out in Figure 1, that the optimized structure $\mathbf{4 a}$ is still asymmetric because the two $\mathrm{P}-\mathrm{Cl}$ bond lengths are not identical, 2.341 and $2.286 \AA$, respectively. However, 4a easily leads to an achiral conformer by rotation around the $\mathrm{P}-\mathrm{P}$ bond, which requires a negligible activation energy $\left(\approx 1 \mathrm{kcal} / \mathrm{mol}^{-1}\right) .{ }^{19} \mathrm{Such}$ a facile rotation allows completion of the chiral inversion at the phosphorus center, through a final transition state similar to TS4a. 
From an energetic point of view, TS4a involves a much lower energy than TS2a, $\Delta \mathrm{H}^{\mathrm{TZ}} \mathrm{ZPC}=+29.4$ and $+58.3 \mathrm{kcal}^{\mathrm{mol}}{ }^{-1}$, respectively (Table 1, entries 3,4$)$. This is attributed to the smaller phosphorus-phosphorus lone pair interaction in this biphilic mechanism. Moreover, the pentacoordinate intermediate $4 \mathbf{a}$ is somewhat low in energy, with $\Delta \mathrm{H}^{\mathrm{TZ}} \mathrm{ZPC}=+7.0 \mathrm{kcal} . \mathrm{mol}^{-1}$ (entry 5). While this mechanism would appear more likely than the monomeric "umbrella" inversion or Horner's mechanisms, the activation energy required to reach TS4a is still too high for a room temperature process. The racemization of the chlorophosphines must still involve another mechanism.

If traces of $\mathrm{HCl}$ were present in the medium, for example due to the aminophosphine acidolysis in toluene, ${ }^{20}$ the formation of the pentacoordinate intermediate 5a could be envisaged occurring via the transition state TS5a (Scheme 3c, Figure 1). The racemization would occur if the hydrogen atom of the achiral pentacoordinate intermediate 5a left with one or the other chlorine substituent, leading to a halogen exchange between the chlorophosphine and $\mathrm{HCl}$. From the energetic point of view, this pathway requires $+10.4 \mathrm{kcal}^{\text {.mol- }}$ 1, which is much lower than the energies of the other paths previously envisaged (entry 7). In addition, the intermediate 5a is also more stable than the pentacoordinate species $4 \mathbf{a}, \Delta \mathrm{H}^{\mathrm{TZ}} \mathrm{ZPC}=-1.2$ and +7.0 kcal.mol-1, respectively (entries 5, 8). According to our theoretical results, the thermodynamic pathway of the inversion of configuration for the 
chlorophosphine 1a, can be sketched by the symmetric curve in Figure 2. The $\mathrm{HCl}$, which acts as a catalyst, is released at the end of the reaction.

Figure 2

It is noteworthy that this reaction mechanism passes through a hydrogen-bonded complex $\mathbf{1 a} \cdot \mathbf{H C l}$ with such a small bonding energy that it is entropically disfavored, as shown by the enthalpy and the free energy values for the reaction: $\Delta \mathrm{H}^{\mathrm{TZ}} \mathrm{ZPC}=-2.7 \mathrm{kcal} . \mathrm{mol}^{-1}$ and $\Delta \mathrm{G}^{298}=+4.2 \mathrm{kcal} . \mathrm{mol}^{-1}$ (entry 6). As for proton transfer from the $\mathrm{HCl}$ moiety to the phosphorus, we expected $\mathbf{1} \mathbf{a} \cdot \mathbf{H C l}$ to convert into the phosphonium salt $\mathbf{6 a}$ before racemization via the achiral pentacoordinate species 5a (Scheme 4). While the ionic species 6a could not be found in the gas phase calculations (the optimization leads directly back to $\mathbf{1 a} \cdot \mathbf{H C l}$ ), such a mechanism can not be totally excluded in solution, if the solvent favors ion pairs (polar solvent).

Scheme 4

Finally, our theoretical studies show that acidolysis conditions ( $\mathrm{HCl})$ catalyze the racemization of the chlorophosphines as they are formed. The inversion of the chlorophosphine is analogous to a halogen exchange, and should thus occur with other halides.

\section{Chlorophosphine halide exchange}


In this context, and in order to illustrate this racemization, we performed complementary computational and experimental studies on the reaction of achiral chlorophosphines $\mathbf{1 a - c}$ with $\mathrm{HBr}$ (Scheme 5).

Scheme 5

\section{Experimental studies}

Experimentally, the halide exchanges with diphenyl- or di-t-butylchlorophosphines (1b or $\mathbf{1 c})$ were performed in toluene, using $\mathrm{HBr}(0.65 \mathrm{M}$ in toluene). The conversions, determined by ${ }^{31} \mathrm{P}$ NMR, are summarized in Table 2. With the addition of half an equiv of $\mathrm{HBr}$, the chlorodiphenylphosphine $\mathbf{1} \mathbf{b}$ was partially converted into the corresponding bromo derivative $\mathbf{7 b}$ (entry 1). 21 The proportion of the products did not change after 30 minutes. When one equiv of $\mathrm{HBr}$ was added to $\mathbf{1 b}$, a complete conversion into the bromodiphenylphosphine $\mathbf{7 b}$ was observed in two minutes at room temperature (entry 2). For the same reaction performed at $-70^{\circ} \mathrm{C}$, the conversion into $\mathbf{7 b}$ reached $85 \%$ in 2 min., thus demonstrating the ease of the halide exchange (entry 3 ). On the other hand, when 5 equiv of $\mathrm{HCl}$ were added to a toluene solution of $\mathbf{7 b}$, the reverse formation of the chlorodiphenylphosphine $\mathbf{1} \mathbf{b}$ was less than $20 \%$ after $14 \mathrm{~h}$ at room temperature.

Although no intermediate species, e.g., a pentacoordinated or a tetracoordinated phosphorus, was clearly identified by ${ }^{31} \mathrm{P}$ NMR, we observed a facile halide exchange on the chlorodiphenylphosphine even at $-70^{\circ} \mathrm{C}$. This 
is in good agreement with the $\mathrm{HCl}$ catalyzed racemization mechanism, discussed in the theoretical section.

In addition, the halide exchange was studied with LiBr. When one equiv of LiBr was used, $\mathbf{1 b}$ afforded the corresponding bromodiphenylphosphine $\mathbf{7 b}$ with a conversion of only $40 \%$ after 90 min at room temperature (entry 4 ). The lower efficiency of $\mathrm{LiBr}$ with respect to $\mathrm{HBr}$, could be explained by the heterogeneity of the reaction mixture. Using four equiv of dry LiBr, the conversion of $\mathbf{1 b}$ was complete within the same reaction time (entry 5). When

the halide exchange was carried out using the di-t-butylchlorophosphine 1c and $\operatorname{LiBr}$ (4 equiv), a complete conversion into $\mathbf{7} \mathbf{c}$ was obtained in $30 \mathrm{~min}$ (entry 6).

Table 2

\section{Computational studies}

The computational study of this halide exchange reaction was carried out with the chlorodimethylphosphine $\mathbf{1 a}$ as a model of the chlorophosphine used experimentally (1) and $\mathbf{1 c}$ ), reacting with $\mathrm{HBr}$. We applied the same levels of calculation previously used.

Table 3 \& Figure 3

The results for the halide exchange are displayed in Table 3 and Figure 3 for the energies and geometries, respectively. After a weak preliminary 
hydrogen-bonded complex $\mathbf{1 a} \cdot \mathbf{H B r}$, the first transition state TS8a is found lower in energy $\left(\Delta \mathrm{H}^{\mathrm{TZ}} \mathrm{ZPC}=+6.0 \mathrm{kcal} . \mathrm{mol}^{-1}\right.$; Table 3, entry 3$)$ than the corresponding $\mathrm{HCl}$ analogue TS5a, (+10.4 kcal.mol-1; Table 1, entry 7). The rest of the reaction profile with $\mathrm{HBr}$ is closer to that of the $\mathrm{HCl}$ analogue. The pentacoordinated intermediate $\mathbf{8 a}$ and the second transition state $\mathbf{T S 8} \mathbf{a}^{\prime}$ are only very slightly lower in energy than those obtained with $\mathrm{HCl}$ (Table 3, entries 4, 5; Table 1, entries 7,8). Finally, the reaction goes through a weak hydrogen-bonded complex $\mathbf{7 a} \cdot \mathbf{H C l}$ to give the products of the halide exchange $(\mathrm{Me})_{2} \mathrm{PBr}(7 \mathbf{a})$ and $\mathrm{HCl}$. The thermodynamic pathway of the halide exchange is shown in Figure 4, and it is noteworthy that the products are slightly lower in energy than the reactants: $\Delta \mathrm{H}^{\mathrm{TZ}} \mathrm{ZPC}=-1.2 \mathrm{kcal} . \mathrm{mol}^{-1}$. The computational results are thus in favor of an easy conversion of the chlorodimethylphosphine $1 \mathbf{a}$ into its bromide derivative $\mathbf{7 a}$, and are in good agreement with the experiments. The thermodynamic pathways of the halogen exchange of $\mathbf{1 a}$ with $\mathrm{HCl}$ or with $\mathrm{HBr}$ are very similar (Figures 2, 4). As $\mathrm{HBr}$ reacts with the chlorophosphines $\mathbf{1 a}$ to lead to the corresponding bromophosphines $\mathbf{7 a}, \mathrm{HCl}$ is also expected to perform the halide exchange, and consequently the racemization.

\section{Reaction of the diastereomerically pure aminophosphine 9 with $\mathrm{HCl}$}

In connection with our continued work on chiral phosphorus borane chemistry, 22 we have investigated the stereoselective synthesis of the Pchirogenic chlorophosphine $\mathbf{1 f}$ by $\mathrm{HCl}$ acidolysis of the diastereomerically

pure aminophosphine 9 (Scheme 6). The stereoselectivity of the acidolysis 
was determined by chemical correlation with the PAMP borane $\mathbf{1 0} \cdot \mathbf{B} \mathbf{H}_{3}$ or the tungsten pentacarbonyl $\mathbf{1 0} \cdot \mathbf{W}(\mathbf{C O})_{5}$ complexes, by quenching $\mathbf{1 f}$ with methyllithium and complexation with the $\mathrm{BH}_{3}$. DMS or $\mathrm{W}(\mathrm{CO})_{5}$. THF. The complexation of the $o$-anisylmethylphenylphosphine $\mathbf{1 0}$ is well established to proceed with retention of the configuration. 23,24

Scheme 6

However, both $\mathbf{1 0} \cdot \mathbf{B H} \mathbf{H}_{3}$ and $\mathbf{1 0} \cdot \mathbf{W}(\mathbf{C O})_{5}$ complexes were obtained as quasi-racemic, and this result was not dependent on the reaction time $(10 \mathrm{~min}$ - $1 \mathrm{~h})$ or the $\mathrm{HCl}$ concentration $(0.04-0.12 \mathrm{M}$ in toluene). As P(III)-chirogenic compounds usually react stereoselectively with organolithium reagents, ${ }^{25}$ and in agreement with our computed and experimental studies, the racemization must originate from the reaction of the chlorophosphine with residual $\mathrm{HCl}$.

\section{Conclusion}

In this dual experimental and computational study on the configurational stability of the chlorophosphines, we have shown that $\mathrm{HCl}$ acts as a catalyst for the inversion at the P-center. The mechanism of the racemization is explained by the phosphorus nucleophilic attack on $\mathrm{H}$, with a concerted backside attack by the chlorine on the phosphorus center. The reaction intermediate, as indicated by the gas phase computation, is an achiral pentacoordinated phosphorus with two chlorine atoms in the axial position. 
Other mono or dimeric mechanisms that we envisaged required too high activation energies for a room temperature process.

The experiments and the calculations on the $\mathrm{HBr}$ reaction with chlorophosphines showed an easy halide exchange, which corroborates the easy racemization of the $\mathrm{P}$-chirogenic analogue. Thus, bromophosphines were easily obtained under mild conditions by simple halide exchange, constituting a practical method for their synthesis.

Finally, we showed that pure chlorophosphines would be configurationally stable at the phosphorus atom, but that traces of acids (HX) or halides, that are almost unavoidable in the experimental conditions, carry out no stereoselectivity for the aminophosphine reaction with $\mathrm{HX}$.

\section{Experimental Section}

All reactions were carried out under an argon or nitrogen atmosphere in dried glassware. THF and toluene were dried and freshly distilled under a nitrogen atmosphere over sodium/benzophenone. Hexane and ethanol for HPLC were of chromatographic grade and were used without further purification. $n$ Butyllithium, 2-bromoanisole, (+)-ephedrine, $\mathrm{BH}_{3} \cdot \mathrm{S}\left(\mathrm{CH}_{3}\right)_{2}, \quad$ DABCO, chlorodiphenylphosphine and di-t-butylchlorophosphine were purchased from Aldrich, Acros and Avocado. Commercially available 2-bromoanisole was distilled before use. $\mathrm{HBr}$ in toluene was prepared by bubbling the gas previously generated by reaction of concentrated sulfuric acid with $\mathrm{NaBr}$, and titrated before use. HPLC analyses were performed on a Gilson 305/306 chromatograph equipped with a UV 116 detector. Flash chromatography was 
performed on silica gel (60AC.C, 35-70 mm; SDS) or neutral aluminum oxide (Carlo Erba; ref. 417241). All NMR spectra were recorded on a Bruker DPX 250 spectrometer, with the deuterium signal of the solvent as the lock, TMS as the internal reference for ${ }^{1} \mathrm{H}(250 \mathrm{MHz})$ and ${ }^{13} \mathrm{C} \mathrm{NMR}(62.9 \mathrm{MHz})$ and $85 \%$ phosphoric acid as the external reference for ${ }^{31} \mathrm{P}$ NMR $(101.3 \mathrm{MHz})$. The ${ }^{31} \mathrm{P}$ NMR chemical shifts $(\delta)$ are calculated as negative values upfield of phosphoric acid. IR spectra were recorded on a Perkin Elmer 1600 FT or a Bruker Equinox 55 spectrometer. Melting points were measured on a Büchi melting point apparatus and are uncorrected. Optical rotation values were determined at $20{ }^{\circ} \mathrm{C}$ on a Perkin-Elmer 241 polarimeter. Mass spectral analyses were performed on a JEOL MS 700 at the Mass Spectroscopy Laboratories of ENS Paris. Elemental analyses were measured with a precision superior to $0.4 \%$ at the Microanalysis Laboratories of P. \& M. Curie University (Paris).

\section{$(R p)-(-)-N-M e t h y l-N-[(1 S, 2 R)-(1-a c e t o x y-2-m e t h y l-1-p h e n y l p r o p-2-y l)]$}

amino-o-anisylphenyl phosphine 9. This compound was obtained by decomplexation from its borane complex, previously prepared from (+)ephedrine according to the published procedure. $22 \mathrm{i}$ In a two-necked flask equipped with a reflux condenser, a magnetic stirrer and an argon inlet, $500 \mathrm{mg}$ (1.15 mmol) of borane complex, $515 \mathrm{mg}(4.6 \mathrm{mmol})$ of diazabicyclooctane were dissolved in $10 \mathrm{~mL}$ of dry and degassed toluene. The mixture was heated at 50 ${ }^{\circ} \mathrm{C}$ for 10 hours. The crude product was rapidly filtered off on a neutral alumina column (15 cm height, $2 \mathrm{~cm}$ diameter) using toluene/AcOEt 9:1 as eluent, to give $444 \mathrm{mg}$ of 9 (yield $91 \%$ ). Colorless viscous oil; ${ }^{1} \mathrm{H}$ NMR $\left(\mathrm{CDCl}_{3}\right): \delta 0.5-$ 
$2.0\left(3 \mathrm{H}, \mathrm{br}, \mathrm{BH} \mathrm{H}_{3}\right), 1.30\left(3 \mathrm{H}, \mathrm{d},{ }^{3} \mathrm{~J}_{\mathrm{HH}}=7, \mathrm{CHCH}_{3}\right), 1.93\left(3 \mathrm{H}, \mathrm{s}, \mathrm{CH}_{3} \mathrm{CO}\right), 2.22$ $\left(3 \mathrm{H}, \mathrm{d},{ }^{3} J_{\mathrm{HH}}=3, \mathrm{NCH}_{3}\right), 3.60\left(\mathrm{~s}, \mathrm{OCH}_{3}\right), 3.90\left(1 \mathrm{H}, \mathrm{m},{ }^{3} J_{\mathrm{HH}}={ }^{3} J_{\mathrm{PH}}=7,{ }^{3} J_{\mathrm{HH}}=\right.$ 8, $\mathrm{NCH}), 5.75\left(1 \mathrm{H}, \mathrm{d},{ }^{3} J_{\mathrm{HH}}=8, \mathrm{PhCH}\right), 6.54(1 \mathrm{H}, \mathrm{m}, H$ arom $), 7.84-7.34(13 \mathrm{H}$, $\mathrm{m}, H$ arom $) ;{ }^{13} \mathrm{C}$ NMR $\left(\mathrm{CDCl}_{3}\right): \delta 15.9\left(\mathrm{~d},{ }^{3} J_{\mathrm{PNCC}}=6, \mathrm{CHCH}_{3}\right), 21.2$ $\left(C \mathrm{H}_{3} \mathrm{CO}\right), 31.9\left(\mathrm{~d},{ }^{2} J_{\mathrm{PNC}}=9, \mathrm{NCH}_{3}\right), 55.1\left(\mathrm{OCH}_{3}\right), 63.5\left(\mathrm{~d},{ }^{2} J_{\mathrm{PNC}}=40, \mathrm{NCH}\right)$, $78.4\left(\mathrm{~d},{ }^{3} J_{\mathrm{PNCC}}=9, C \mathrm{HO}\right), 109.9(C$ arom $), 120.6(C$ arom $), 125.2-129.9(C$ arom), $131.3\left(\mathrm{~d}, J_{\mathrm{PC}}=19, C\right.$ arom $), 131.8\left(\mathrm{~d}, J_{\mathrm{PC}}=3, C\right.$ arom $), 138.1\left(\mathrm{~d}, J_{\mathrm{PC}}=7\right.$, $C$ arom), $139.1(C$ arom $), 160.4\left(\mathrm{~d}, J_{\mathrm{PC}}=17, C\right.$ arom $), 170.1(C$ arom $) ;{ }^{31} \mathrm{P}$ $\operatorname{NMR}\left(\mathrm{CDCl}_{3}\right): \delta+56$.

\section{Preparation of $o$-anisylchlorophenylphosphine 1f:}

In a $100 \mathrm{~mL}$ two-necked flask equipped with a magnetic stirrer, an argon inlet and a rubber septum, $600 \mathrm{mg}$ of the aminophosphine 9 (0.95 mmol) was dissolved in $32.5 \mathrm{~mL}$ of toluene. A solution of $\mathrm{HCl}$ in toluene $(0.37 \mathrm{M}, 5.3 \mathrm{ml}, 2$ mmol) was added at room temperature with stirring. After $1 \mathrm{~h}$, the ephedrine hydrochloride was filtered off on a millipore $4 \mu \mathrm{m}$ filter, and the solution of $\mathbf{1 f}$ was used immediately without further purification.

Correlation to PAMP.BH $3, \mathbf{1 0} \cdot \mathbf{B H}_{3}{ }^{22 \mathrm{f}}$ and PAMP.W $(\mathrm{CO})_{5}, \mathbf{1 0} \cdot \mathbf{W}(\mathbf{C O})_{5}{ }^{24}$

The previous filtrate was then cooled to $-78^{\circ} \mathrm{C}$, and $2.2 \mathrm{~mL}$ of $\mathrm{MeLi}$ $(1.33 \mathrm{M})$ was added. The reaction was kept at this temperature for $30 \mathrm{~min}$, after which the cooling bath was removed and the temperature allowed to warm to 
RT. Half of the reaction mixture was quenched by $0.5 \mathrm{~mL} \mathrm{BH}_{3}$. DMS (10M). After hydrolysis, the solvent was removed under reduced pressure, and the aqueous layer was extracted with $3 \times 25 \mathrm{~mL}$ of $\mathrm{CH}_{2} \mathrm{Cl}_{2}$. The combined extracts were dried over $\mathrm{MgSO}_{4}$, and concentrated under reduced pressure. The residue was purified by chromatography on a short column of silica gel with a toluene/petroleum ether: $7 / 3$ mixture as eluent to give $50 \mathrm{mg}$ of $\mathbf{1 0} \cdot \mathbf{B} \mathbf{H}_{\mathbf{3}}(43 \%$ yield). The enantiomeric excess of the PAMP.BH 3 complex $\mathbf{1 0} \cdot \mathbf{B H}_{3}$ (e.e. $3 \%$ ) was determined by HPLC on a Chiralcel OK Daicel column with hexane/EtOH: $70 / 30$ as eluent (flow rate $1 \mathrm{~mL} \cdot \min ^{-1} ;(S)$ enantiomer $\mathrm{t}_{\mathrm{R}}=10.9 \mathrm{~min} ;(R)$ enantiomer $\left.t_{R}=19.5 \mathrm{~min}\right)$.

The second half of the reaction mixture $(\sim 20 \mathrm{~mL})$ was quenched by $8.5 \mathrm{~mL}$ of a freshly prepared solution of $\mathrm{W}(\mathrm{CO})_{5}$. THF $(0.05 \mathrm{M})$. After 2 hours, the reaction mixture was hydrolyzed, and the solvent removed under reduced pressure. After extraction of the aqueous layer with $3 \times 25 \mathrm{~mL}$ of $\mathrm{CH}_{2} \mathrm{Cl}_{2}$, the combined extracts were dried over $\mathrm{MgSO}_{4}$, then concentrated. The residue was purified by chromatography on a column of silica gel with a cyclohexane/AcOEt $15 / 1$ mixture as eluent to give $96 \mathrm{mg}$ of $\mathbf{1 0} \cdot \mathbf{W}(\mathbf{C O})_{5}(36 \%$ yield $):$ o.p. $<2 \%$; $[\alpha]_{\mathrm{D}}^{20}=-0.95\left(\mathrm{c} 0.5, \mathrm{CHCl}_{3}\right) ;$ litt. $^{24}[\alpha]_{\mathrm{D}}^{20}=-77\left(\mathrm{c} 2.3, \mathrm{CHCl}_{3}\right)$.

Halide exchange with the chlorophosphines $1 \mathrm{~b}, 1 \mathrm{c}$

Typical procedure for HBr reaction: preparation of the bromo diphenylphosphine $7 \mathrm{~b}$ : 
In a $50 \mathrm{~mL}$ two-necked flask equipped with a magnetic stirrer, an argon inlet and a rubber septum, $0.9 \mathrm{~mL}$ of freshly distilled chlorodiphenylphosphine 1 b $\left[5 \mathrm{mmol} ;{ }^{31} \mathrm{P} \mathrm{NMR}\left(\mathrm{CDCl}_{3}\right): \delta+82\right]$ was added to $14 \mathrm{~mL}$ of $\mathrm{HBr}$ in toluene (0.65 M, $9 \mathrm{mmol})$. After stirring at room temperature for 15 minutes, $31 \mathrm{P}$ NMR analysis revealed complete conversion into $\mathbf{7 b}$. After removal of the solvent under vacuum, the orange oily residue was distilled under vacuum (0.08 mbar) to give $700 \mathrm{mg}$ as the main fraction (isolated yield $53 \%$ ).

${ }^{1} \mathrm{H} \mathrm{NMR}\left(\mathrm{CDCl}_{3}\right): \delta 7.33-7.36(6 \mathrm{H}, \mathrm{sl}, H$ arom $), 7.57-7.65(4 \mathrm{H}, \mathrm{sl}, H$ arom $)$; ${ }^{13} \mathrm{C} \operatorname{NMR}\left(\mathrm{CDCl}_{3}\right): \delta 128.5\left(\mathrm{~d},{ }^{2} J_{\mathrm{PCC}}=7\right.$, Cortho $), 130.2(\mathrm{~s}$, Cpara $), 132.5(\mathrm{~d}$, ${ }^{3} J_{\mathrm{PCCC}}=24$, Cmeta $), 137.0\left(\mathrm{~d},{ }^{1} J_{\mathrm{PC}}=36\right.$, Cipso $) ;{ }^{31} \mathrm{P} \mathrm{NMR}\left(\mathrm{CDCl}_{3}\right): \delta+72$; Lit. $26+72.4$

Typical procedure for LiBr reaction: preparation of the bromo-di-tbutylphosphine $7 \mathrm{c}$ :

In a $50 \mathrm{~mL}$ two-necked flask equipped with a magnetic stirrer, an argon inlet and a rubber septum, $0.5 \mathrm{~mL}$ of freshly distilled di-t-butylchlorophosphine 1c $\left[2.9 \mathrm{mmol} ;{ }^{1} \mathrm{P} \mathrm{NMR}\left(\mathrm{CDCl}_{3}: \delta+146\right]\right.$, and $1.05 \mathrm{~g}$ of $\operatorname{LiBr}(11.6 \mathrm{mmol}, 4$ equiv) was added to $3 \mathrm{~mL}$ of dry toluene $(0.65 \mathrm{M}, 9 \mathrm{mmol})$. After stirring at room temperature for 30 minutes, ${ }^{31} \mathrm{P}$ NMR analysis revealed complete conversion into $\mathbf{7 c}$.

${ }^{31} \mathrm{P} \operatorname{NMR}\left(\mathrm{CDCl}_{3}\right): \delta+150 ;$ Lit. ${ }^{27}+152$ 


\section{Acknowledgements}

This work was supported by a substantial allocation of computing time from CRIHAN - Plan Interrégional du Bassin Parisien - Pôle interrégional de modélisation en sciences pour l'ingénieur, project 2001-2003, and by the computational center of the Université of Reims Champagne-Ardenne. The authors gratefully acknowledge also the Regions Champagne Ardennes (Fellowship for C.B.) and Bourgogne, the ministry of research and the CNRS for their financial support.

\section{Supplementary materials available}

XYZ coordinates for all the computed structures, 13 pages. 


\section{References and notes}

(1) (a) Brunner, H. and Zettlmeier, W. Handbook of Enantioselective Catalysis with Transition Metal Compounds, Products and Catalysis, Vol. 1, VCH, Basel, 1993. (b) Ojima, I. Catalytic Asymmetric Synthesis, VCH, New York, 1993. (c) Noyori, R. Asymmetric Catalysis in Organic Synthesis, Wiley \& Sons, New York, 1994. (d) Palmer, M.J.; Wills, M. Tetrahedron: Asymmetry 1999, 10, 2045-2061. (e) Tenaglia, A.; Heumann, A. Angew. Chem. Int. Ed. Engl. 1999, $38,2180-2184$.

(2) Brunner, H. and Zettlmeier, W. Handbook of Enantioselective Catalysis with Transition Metal Compounds, Ligands-References, Vol. 2, VCH, Basel, 1993.

(3) For recent, selected examples of enantioselective catalysis using diphosphine ligands, see: (a) Trost, B.M.; Toste, F.D. J. Am. Chem. Soc. 1999, 121, 4545-4554. (b) Burk, M.J.; Bienewald, F.; Challenger, S.; Derrick, A.; Ramsden, J.A. J. Org. Chem. 1999, 64, 3290-3298. (c) Blaser, H.U.; Buser, H.P.; Jalett, H.P.; Pugin, B.; Spindler, F. Synlett 1999, 867-868. (d) Zhang, Z.; Zhu, G.; Jiang, Q.; Xiao, D.; Zhang, X. J. Org. Chem. 1999, 64, 1774-1775. (e) Fehr, M.J., Consiglio, G.; Scalone, M.; Schmidt, R. J. Org. Chem. 1999, 64, 5768-5776. (f) Kuwano, R.; Ito, Y. J. Org. Chem. 1999, 64, 1232-1237.

(4) For recent, selected enantioselective catalysis using diphosphinite or diphosphite ligands, see: (a) Clyne, D.S.; Mermet-Bouvier, Y.C.; Nomura, N.; Rajanbabu, T.V.J.Org. Chem. 1999, 64,7601-7611. (b) Hu, W.; Yan, M.; Lau, C.P.; Yang, S.M.; Chan, A.S.C.; Jiang, Y.; Mi, A. Tetrahedron Lett. 1999, 40, 
973-976. (c) Chen, Y.; Li. X.; Tong, S.K.; Choi, M.C.K.; Chan, A.S.C. Tetrahedron Lett. 1999, 40, 957-960. (d) Kündig, E.P.; Saudan, C.M.; Bernardinelli, G. Angew. Chem. Int. Ed. Engl. 1999, 38, 1220-1223. (e) Reetz, M.T.; Mehler, G. Angew. Chem. Int. Ed. Engl. 2000, 39, 3889-3890. (f) Diéguez, M.; Pàmies, O.; Ruiz, A.; Castillon, S.; Claver, C. Chem. Eur. J. 2001, 7, 3086-3094.

(5) (a) Agbossou, F.; Carpentier, J.F.; Hapiot, F.; Suisse, I.; Mortreux, A. Coord. Chem. Rev. 1998, 178-180,1615-1645. (b) Devocelle, M.; Mortreux, A.; Agbossou, F.; Dormoy, J. R. Tetrahedron Lett. 1999, 40, 4551-4554.

(6) For a recent review on chelating monophosphines or derivative ligands, see: Lagasse, F.; Kagan, H.B. Chem. Pharm. Bull. 2000, 48(3), 315-324.

(7) For selected examples of the synthesis of phosphorus ligands using chlorophosphine as an electrophilic block, see: (a) Sprinz, J; Helmchen, G. Tetrahedron Lett. 1993, 34, 1769-1772. (b) Deaton, D.N. in Encyclopedia of Reagents for Organic Synthesis, Paquette, L.A. Ed., Vol. 2, Wiley, Chichester, 1995. (c) See also ref. 4, 5.

(8) For a typical synthesis of phosphorus ligands using chlorophosphine as phosphide, see: Peer, M.; de Jong J.C.; Kiefer, M.; Langer, T.; Rieck, H.; Schell, H.; Sennhenn, P.; Sprinz, J.; Steinhagen, H.; Wiese, B.; Helmchen, G. Tetrahedron 1996, 52, 7547-7583.

(9) (a) Rauk, A.; Allen, L.C.; Mislow, K. Angew. Chem. Int. Ed. Engl. 1970, 9, 400-414. (b) Baechler, R.D.; Mislow, K. J. Am. Chem. Soc. 1971, 93, 773-774. 
(10) Levin, C.C. J. Am. Chem. Soc. 1975, 97, 5649-5655.

(11) Omelanczuk, J. J. Chem. Soc., Chem. Commun. 1992, 1718-1719.

(12) The kinetic resolution of $t$-butylchlorophenylphosphine $\mathbf{1 d}$ has been described for the preparation of the (thio)phosphoryl derivative with e.e. up to 50\% in: Perlikowska, W. Gouygou, M.; Daran, J.C.; Balavoine, G.; Mikolajczyk, M.Tetrahedron Lett. 2001, 42, 7841-7845.

(13) Horner, L.; Jordan, M. Phosphorus and Sulfur 1980, 8, 235-242.

(14) (a) For a recent high level computational work on the $\mathrm{S}_{\mathrm{N}} 2$ reactions of halide ions on neutral halophosphines in gas phase, see: Sølling, T.I.; Pross, A.; Radom, L. Int. J. Mass Spectrom. 2001, 210/211, 1-11. (b) For corresponding gas phase measurements, Van Doren, J.M.; DePuy, C.H.; Bierbaum, V.M. J. Phys. Chem. 1989, 93, 1130-1134.

(15) Gaussian 98, Revision A.7, Frisch, M.J.; Trucks, G.W.; Schlegel, H.B.; Scuseria, G.E.; Robb, M.A.; Cheeseman, J.R.; Zakrzewski, V.G.; Montgomery, Jr., J.A.; Stratmann, R.E.; Burant, J.C.; Dapprich, S.; Millam, J.M.; Daniels, A.D.; Kudin, K.N.; Strain, M.C.; Farkas, O.; Tomasi, J.; Barone, V.; Cossi, M.; Cammi, R.; Mennucci, B.; Pomelli, C.; Adamo, C.; Clifford, S.; Ochterski, J.; Petersson, G.A.; Ayala, P.Y.; Cui, Q.; Morokuma, K.; Malick, D.K.; Rabuck, A.D.; Raghavachari, K.; Foresman, J.B.; Cioslowski, J.; Ortiz, J.V.; Baboul, A.G.; Stefanov, B.B.; Liu, G.; Liashenko, A.; Piskorz, P.; Komaromi, I.; Gomperts, R.; Martin, R.L.; Fox, D.J.; Keith, T.; Al-Laham, M.A.; Peng, C.Y.; Nanayakkara, A.; Gonzalez, C.; Challacombe, M.; Gill, P.M.W.; Johnson, B.; 
Chen, W.; Wong, M.W.; Andres, J.L.; Gonzalez, C.; Head-Gordon, M.; Replogle, E. S.; Pople, J.A. Gaussian, Inc., Pittsburgh PA, 1998.

(16) (a) Becke, A.D. J. Chem. Phys. 1993, 98, 5648-5652. (b) Becke, A.D. J. Chem. Phys. 1996, 104, 1040-1046. c) Lee, C.; Yang, W.; Parr, R.G. Phys. Rev. B 1988, 37, 785-789. d) Miehlich, B.; Savin, A.; Stoll, H.; Preuss, H. Chem. Phys. Lett. 1989, 157, 200-206.

(17) (a) Trippett, S. Phosphorus and Sulfur 1976, 1, 89-98. (b) Thatcher, G.R.J.; Campbell, A.S. J. Org. Chem. 1993, 58, 2272-2281. (c) Burgada, R.; Setton, R. in The Chemistry of Organophosphorus Compounds, Hartley, F.R. Ed., Vol. 3, J. Wiley, New York, 1994.

(18) For the concept of biphilicity, which is related to dual electrophilic and nucleophilic properties of the phosphorus center, see: a) Ivanov, B.E.; Zheltukhin, V.F. Russian Chem. Rev. 1970, 39, 358-372. b) Smith, D.J.H. in Comprehensive Organic Synthesis, Sutherland, I.O. Ed, Vol. 2, 1121-1187, Pergamon Press, Oxford, 1979.

(19) More details on this minor aspect of the mechanism are provided in the supplementary materials.

(20) A purely ionic mechanism would require a complete charge separation $\mathrm{H}^{+}$ $+\mathrm{Cl}^{-}$that does not occur in toluene.

(21) The foremost preparation of $\mathbf{7 b}$ by reaction of an excess of $\mathrm{HBr}$ with $\mathbf{1 b}$ has been described by: Dörken, C. Chem. Ber. 1888, 21, 1506-1515. 
(22) (a) Jugé, S.; Stephan, M.; Achi, S.; Genêt, J.P. Phosphorus and Sulfur. 1990, 49/50, 267-270. (b) US Patent 5043465 (1989). (c) Jugé, S.; Stephan, M.; Laffitte, J.A.; Genêt, J.P. Tetrahedron Lett. 1990, 31, 6357-6360. (d) Jugé, S.; Stephan, M.; Genêt, J.P.; Halut-Desportes, S.; Jeannin, S. Acta Cryst. 1990, C46, 1869-1872. (e) Jugé, S.; Stephan, M.; Merdès, R.; Genêt, J.P.; HalutDesportes, S. J. Chem. Soc., Chem. Commun. 1993, 531-533. (f) Kaloun, E.B.; Merdès, R.; Genêt, J.P.; Uziel, J.; Jugé, S. J. Organomet. Chem. 1997, 529, 455-463. (g) Moulin, D.; Darcel, C.; Jugé, S. Tetrahedron : Asymmetry 1999, 10, 4729-4743. (h) Moulin, D.; Bago, S.; Bauduin, C.; Darcel, C.; Jugé, S.Tetrahedron : Asymmetry 2000, 11, 3939-3956. (i) Uziel, J.; Darcel, C.; Bauduin, C.; Moulin, D.; Jugé, S. Tetrahedron : Asymmetry 2001, 12, 1441 1449.

(23) Imamoto, T.; Kusumoto, T.; Suzuki, N.; Sato, K. J. Am. Chem. Soc. 1985, $107,5301-5303$.

(24) Brodie, N.; Jugé, S. Inorg. Chem. 1998, 37, 2438-2442.

(25) (a) Chodkiewicz, W.; Jore, D.; Wodzki, W. Tetrahedron Lett. 1979, 20, 1069-1072. (b) Mikolajzyk, M. Pure \& Appl. Chem. 1980, 52, 959-972. (c) Nielsen, J.; Dahl, O. J. Chem. Soc. Perkin Trans. II 1984, 553-558. (c) Kolodiazhnyi, O.I. Tetrahedron : Asymmetry 1998, 9, 1279-1332.

(26) Lindner, E.; Dieter Merkle, D. Hiller, W.; Fawzi, R. Chem. Ber. 1986, 119 , $659-668$

(27) Du Mont, W.-W; Schumann, H. J. Organomet. Chem. 1977, 128, 99-114. 


\section{Figure Captions}

Figure 1. B3LYP/6-31+G(2d) optimized geometries for transition states or intermediates derived from 1a. Arrows are displayed for the transition state structures (TS2a, TS3a, TS4a and TS5a) to indicate the corresponding reaction coordinates.

Figure 2. Thermodynamic and stereochemical pathway for the phosphorus inversion of a chlorophosphine $\mathbf{1 a}$ with $\mathrm{HCl}$. Energies are in kcal.mol-1

Figure 3. B $3 L Y P / 6-31+G(2 d)$ optimized geometries for the halide exchange between $\mathbf{1 a}$ and $\mathrm{HBr}$. The arrows displayed on the transition state structures (TS8a, TS89'), indicate the reaction coordinates.

Figure 4. Illustration of the two thermodynamic pathways of halogen exchange for $\mathbf{1}$ a with $\mathrm{HBr}$ in gas phase. Energies are in kcal.mol-1. 
Schemes

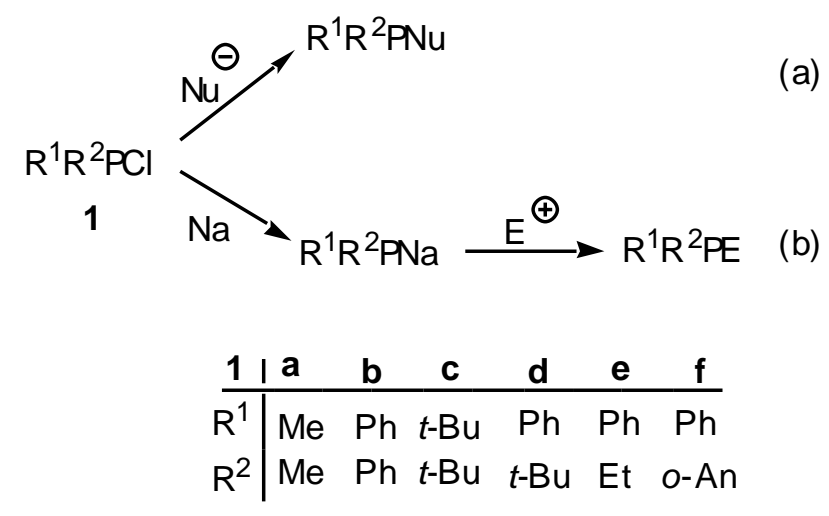

Scheme 1 


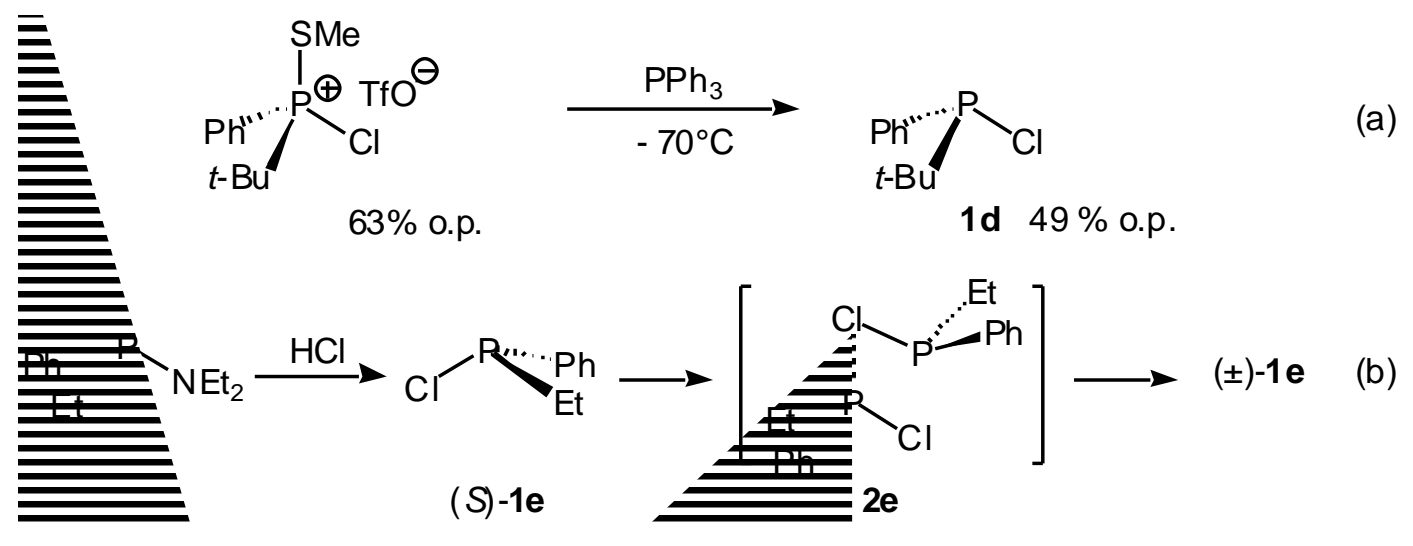

Scheme 2 


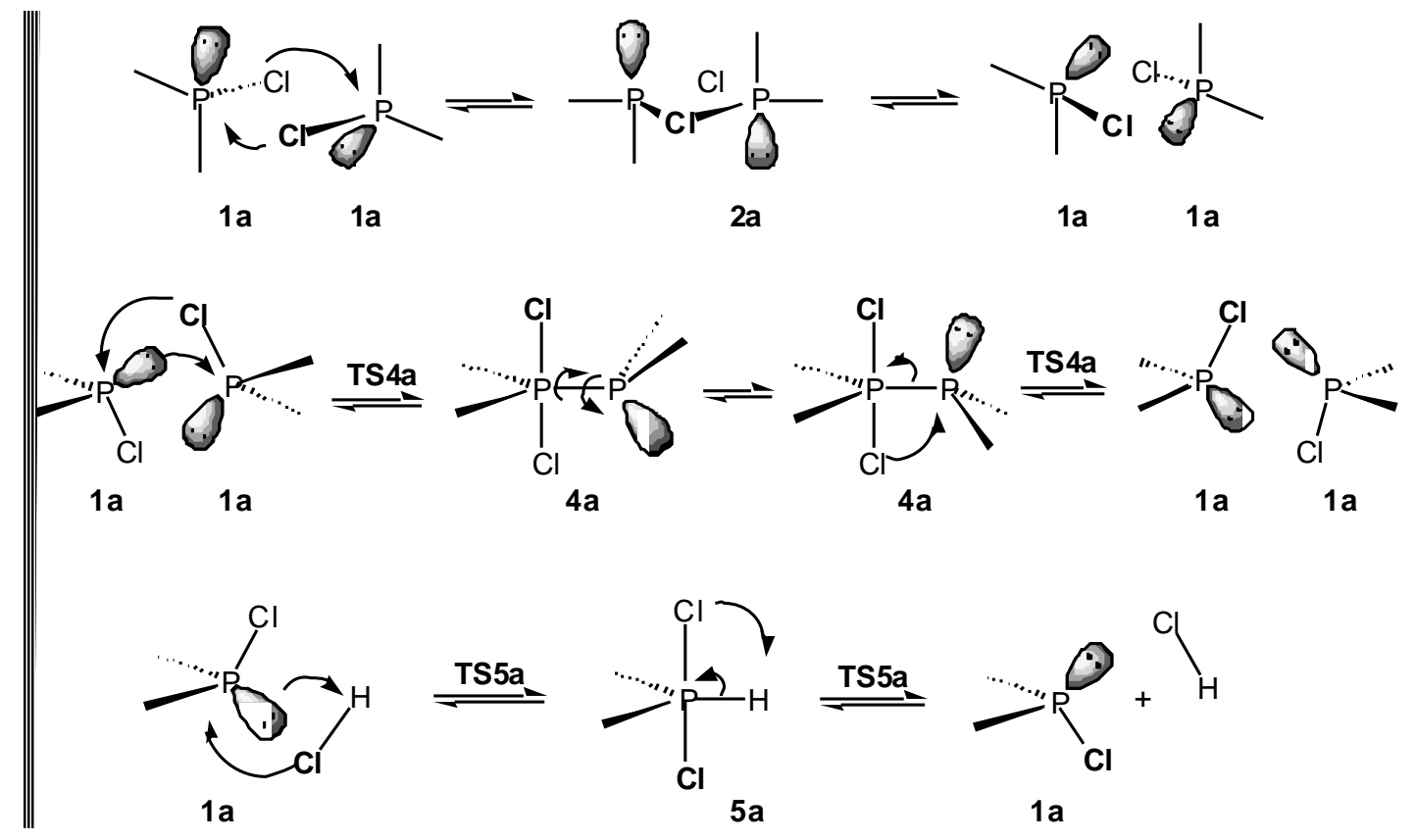

Scheme 3 

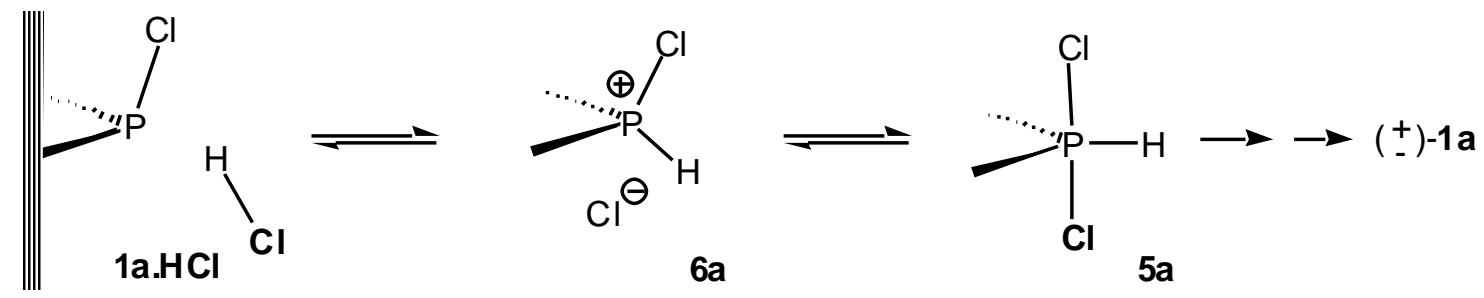

Scheme 4 


$$
\underset{\text { 1a-c }}{\mathrm{R}_{2} \mathrm{PCl}}+\mathrm{HBr} \longrightarrow \underset{7 \text { a-c }}{\mathrm{R}_{2} \mathrm{PBr}+\mathrm{HCl}}
$$

Scheme 5 


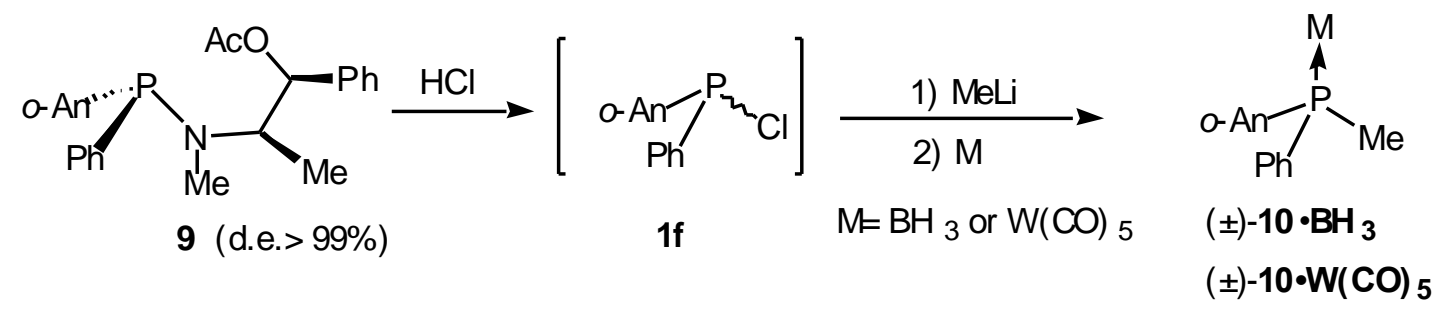

Scheme 6 


\section{Tables}

Table 1. Energy variations in kcal.mol-1, unless otherwise stated, for the transition states and the intermediates displayed in Figure 1.

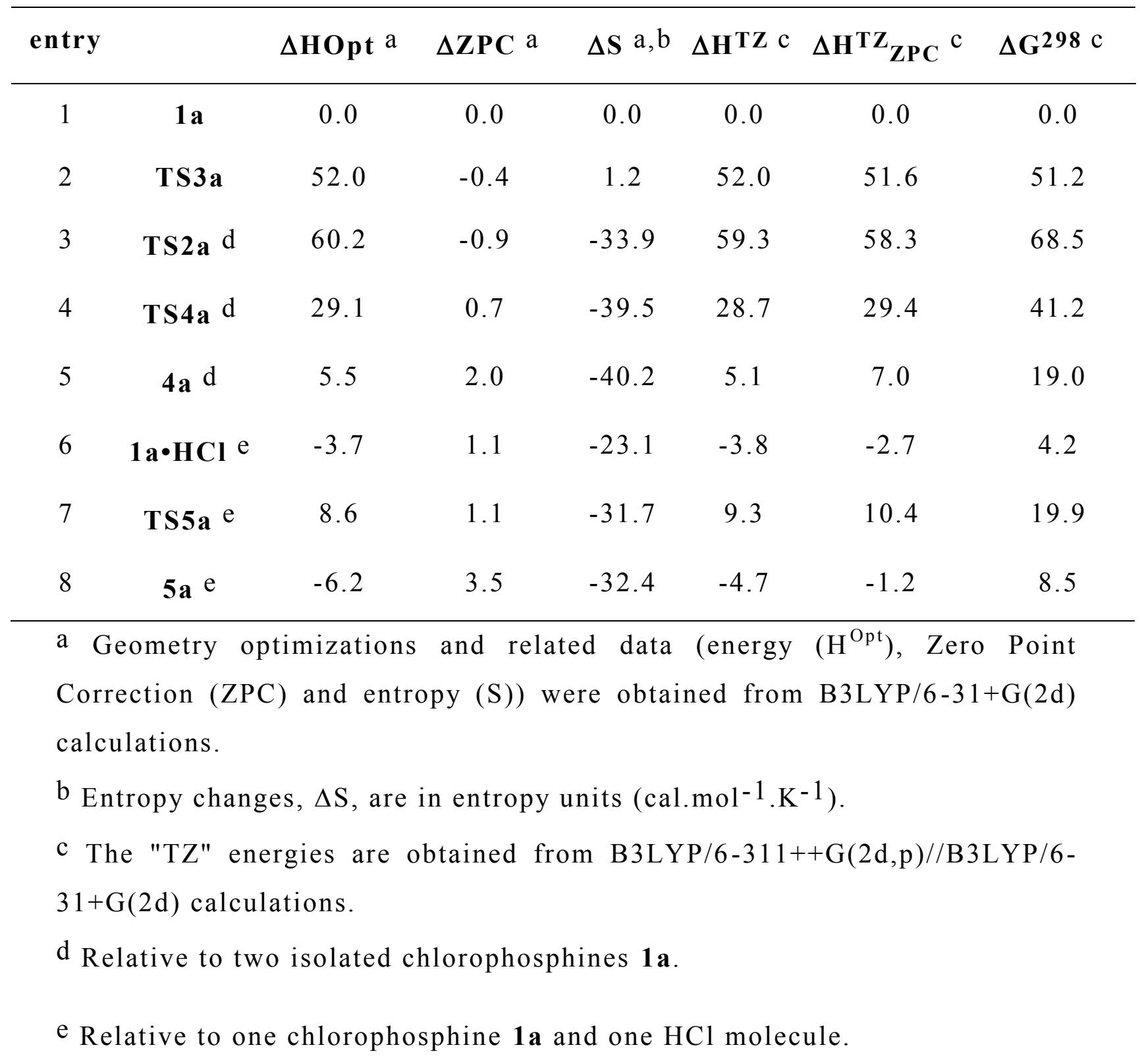


Table 2. Halide exchange with the chlorophosphines $\mathbf{1 b}$ and $\mathbf{1 c}$.

\begin{tabular}{|c|c|c|c|c|c|c|c|}
\hline \multirow[t]{2}{*}{ entry } & \multicolumn{2}{|c|}{$\mathrm{R}_{2} \mathrm{PCl} 1$} & \multicolumn{3}{|c|}{ Experimental conditions a } & \multicolumn{2}{|c|}{$\mathrm{R}_{2} \mathrm{PBr} 7$} \\
\hline & $\mathrm{R}$ & & reagent & $\mathrm{T}^{\circ} \mathrm{C}$ & time $(\min )$ & & conv. $(\%)^{b}$ \\
\hline 1 & $\mathrm{Ph}$ & $1 \mathrm{~b}$ & $\operatorname{HBr}(0.5$ equiv. $)$ & $\mathrm{RT}$ & 45 & $7 \mathbf{b}$ & 50 \\
\hline 2 & $\mathrm{Ph}$ & $1 \mathbf{b}$ & $\operatorname{HBr}$ ( 1 equiv.) & $\mathrm{RT}$ & 2 & $7 \mathrm{~b}$ & 100 \\
\hline 3 & $\mathrm{Ph}$ & $1 \mathbf{b}$ & HBr ( 1 equiv.) & $-70^{\circ} \mathrm{C}$ & 2 & $7 b$ & 85 \\
\hline 4 & $\mathrm{Ph}$ & $1 \mathbf{b}$ & $\operatorname{LiBr}(1 \text { equiv })^{\mathrm{c}}$ & $\mathrm{RT}$ & 90 & $7 \mathbf{b}$ & 40 \\
\hline 5 & $\mathrm{Ph}$ & $1 \mathbf{b}$ & $\operatorname{LiBr}(4 \text { equiv. })^{d}$ & $\mathrm{RT}$ & 90 & $7 \mathrm{~b}$ & 100 \\
\hline 6 & $\mathrm{t}-\mathrm{Bu}$ & $1 \mathrm{c}$ & $\operatorname{LiBr}(4 \text { equiv. })^{d}$ & $\mathrm{RT}$ & 30 & $7 c$ & 100 \\
\hline
\end{tabular}


Table 3. Energy variations in kcal.mol-1, unless otherwise stated, of intermediates and transition states for halide exchange between 1a and $\mathrm{HBr}$. Corresponding structures are displayed in Figure 3. These energies are relative to one chlorophosphine $\mathbf{1 a}$ and one $\mathrm{HBr}$ molecule.

\begin{tabular}{|c|c|c|c|c|c|c|c|}
\hline entry & & $\Delta$ HOpt $^{\mathrm{a}}$ & $\Delta Z \mathbf{P C}$ a & $\Delta \mathbf{S}$ a,b & $\Delta H^{T Z ~ c}$ & $\Delta H^{T Z} Z_{P C}{ }^{\mathrm{c}}$ & $\Delta G^{298}$ \\
\hline 1 & $1 \mathbf{a}+\mathrm{HBr}$ & 0.0 & 0.0 & 0.0 & 0.0 & 0.0 & 0.0 \\
\hline 2 & $1 \mathbf{a} \cdot \mathbf{H B r}$ & -3.8 & 1.1 & -23.7 & -3.2 & -2.1 & 5.0 \\
\hline 3 & TS8a & 3.3 & 1.3 & -32.1 & 4.7 & 6.0 & 15.6 \\
\hline 4 & $8 \mathbf{a}$ & -8.6 & 3.6 & -32.0 & -5.3 & -1.7 & 7.9 \\
\hline 5 & TS8a' & 5.6 & 1.4 & -32.2 & 8.3 & 9.6 & 19.2 \\
\hline 6 & $7 \mathbf{a} \cdot \mathbf{H C l}$ & -7.0 & 1.4 & -23.8 & -5.0 & -3.6 & 3.5 \\
\hline 7 & $7 a+\mathrm{HCl}$ & -3.2 & 0.2 & -0.1 & -1.4 & -1.2 & -1.1 \\
\hline \multicolumn{8}{|c|}{$\begin{array}{l}\text { Correction (ZPC) and entropy }(\mathrm{S})) \text { were obtained from B3LYP/6-31+G(2d) } \\
\text { calculations. }\end{array}$} \\
\hline \multicolumn{8}{|c|}{ b Entropy changes, $\Delta \mathrm{S}$, are in entropy units $\left(\right.$ cal.mol-1. $\left.\mathrm{K}^{-1}\right)$} \\
\hline \multicolumn{8}{|c|}{$\begin{array}{l}\text { c The "TZ" energies are obtained from B3LYP/6-311++G(2d,p)//B3LYP/6- } \\
31+\mathrm{G}(2 \mathrm{~d}) \text { calculations. }\end{array}$} \\
\hline
\end{tabular}


Figures
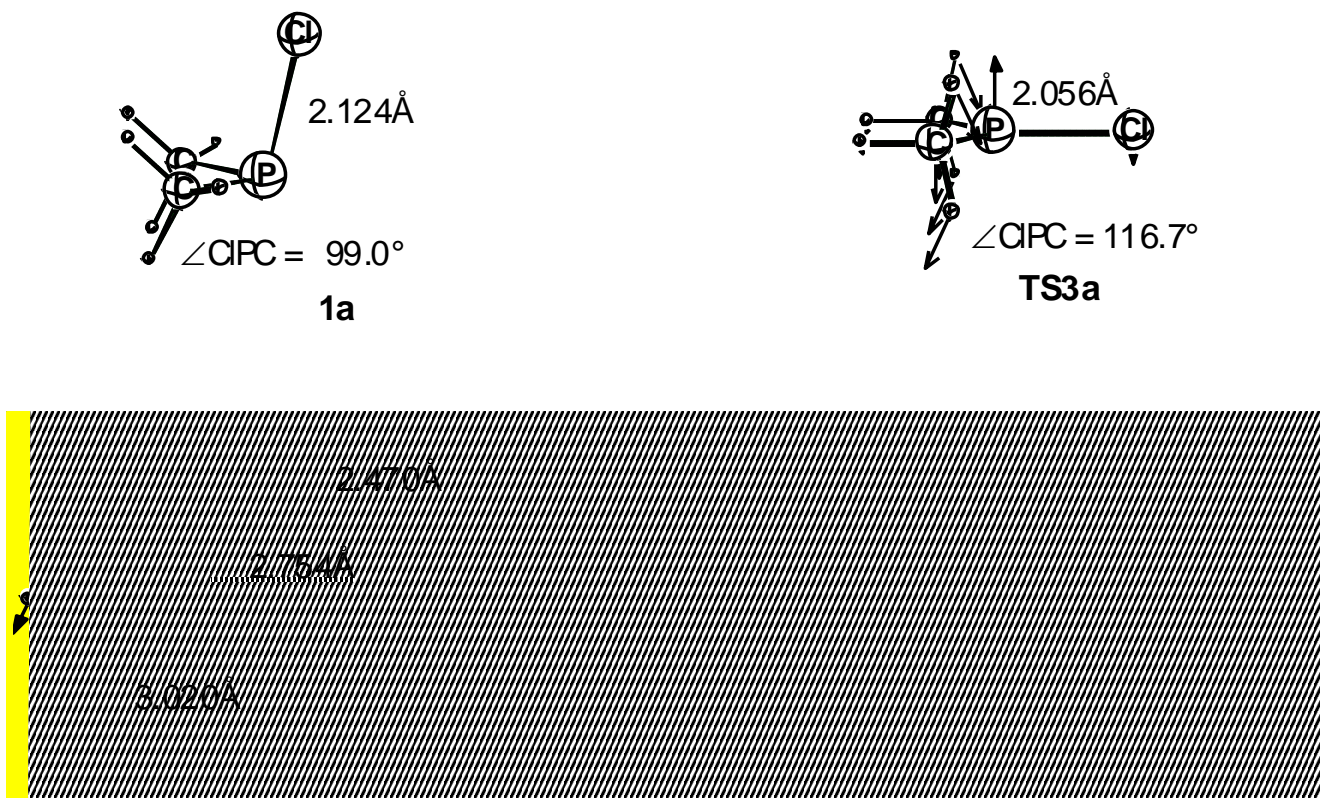

TS2a

TS2a Topview
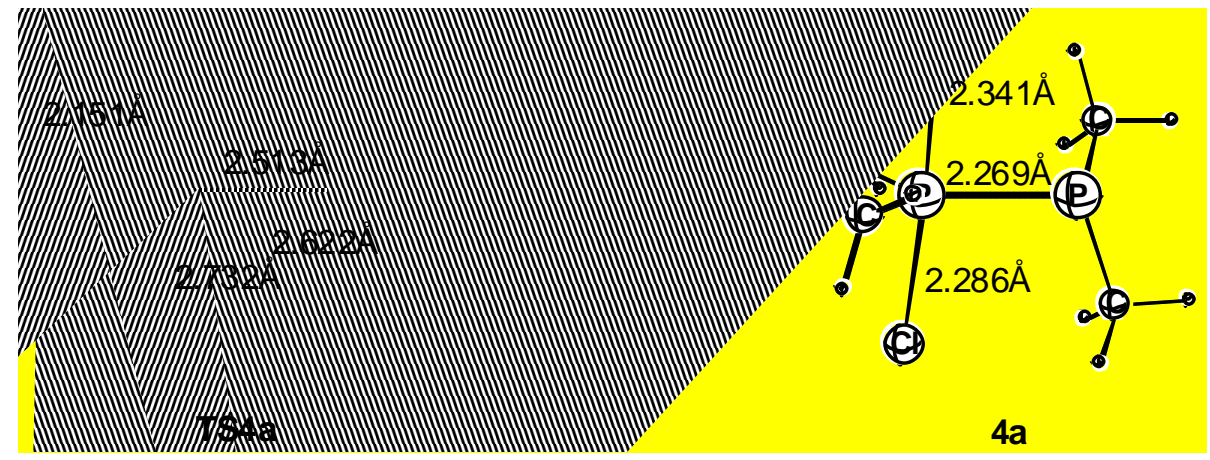

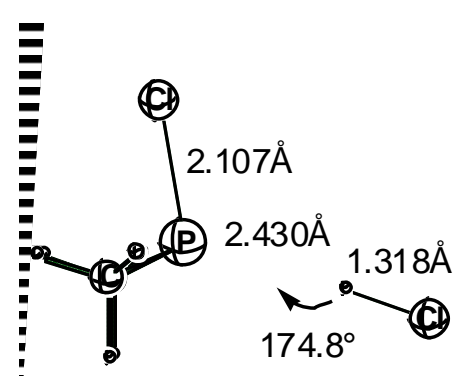

$1 \mathrm{a} \cdot \mathrm{HCl}$

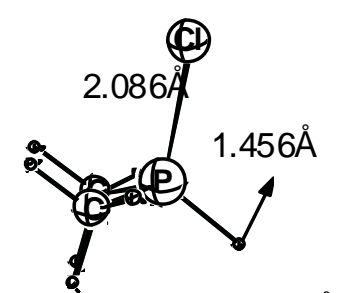

$2.931 \AA$

TS5a

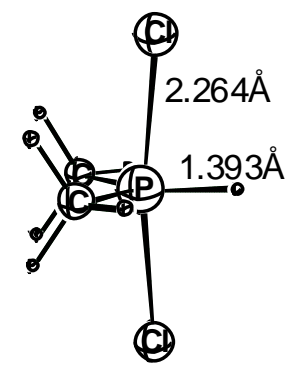

$5 a$ 
Figure 1.

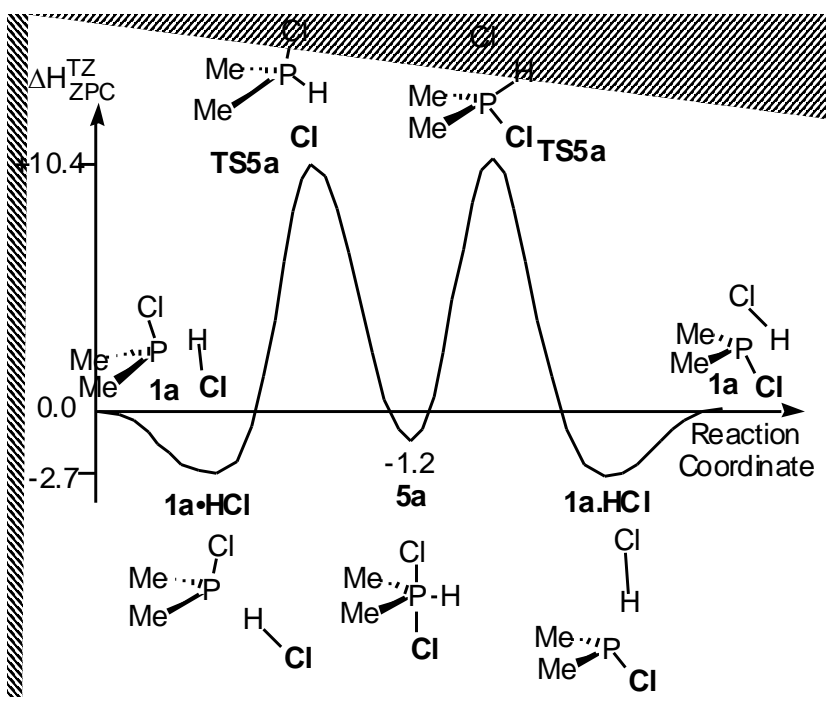

Figure 2. 


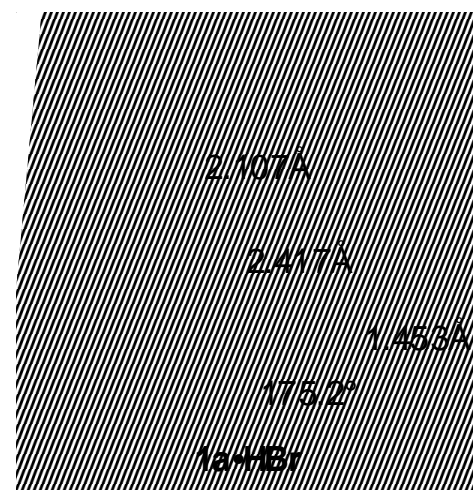

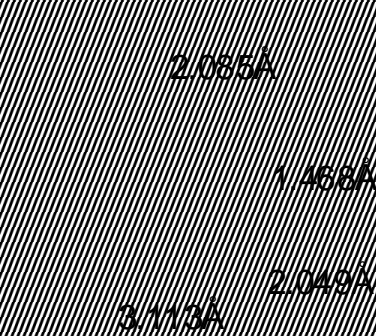

(3)

$\angle \mathrm{PHBr}=123.7^{\circ}$

TS8a

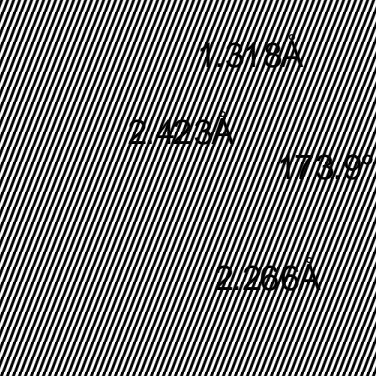

$7 \mathrm{a} \cdot \mathrm{HCl}$

(3)

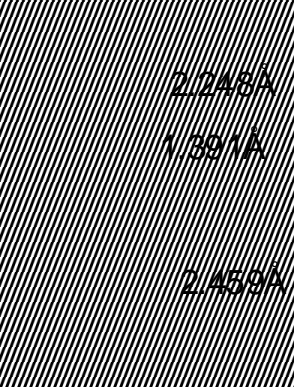

$8 a$
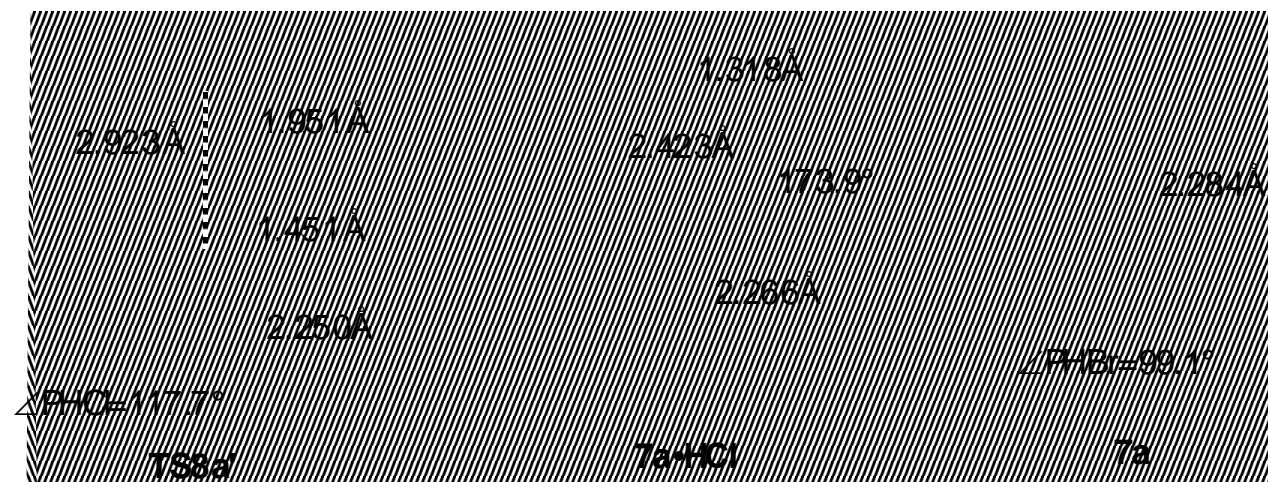

$\angle \mathrm{PHBr}=99.1^{\circ}$

Figure 3. 


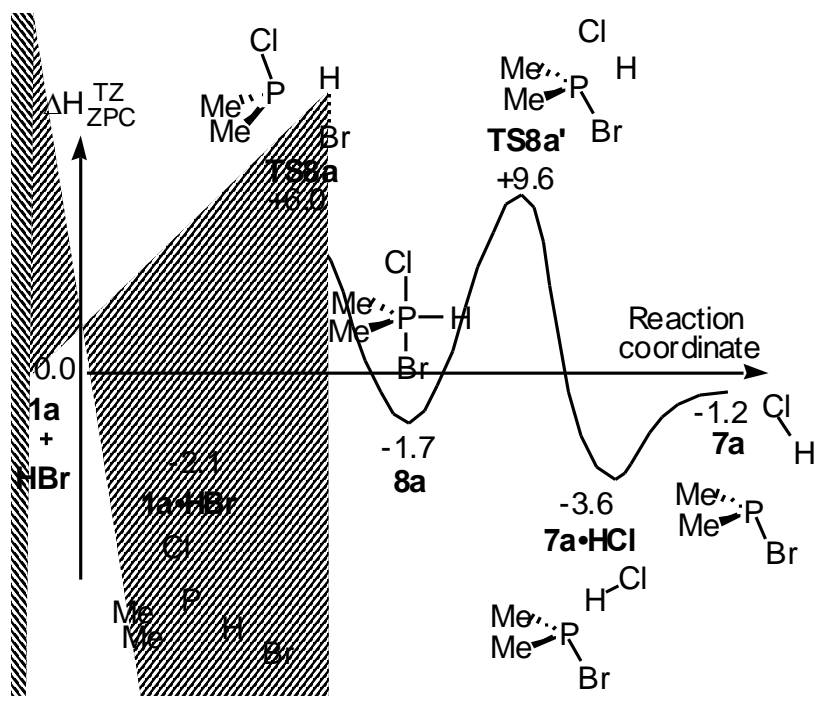

Figure 4. 


\section{TOC Graphic}

On the Configurational Stability of Chlorophosphines

S. Humbel, C. Bertrand, C. Darcel, C. Bauduin and S. Jugé

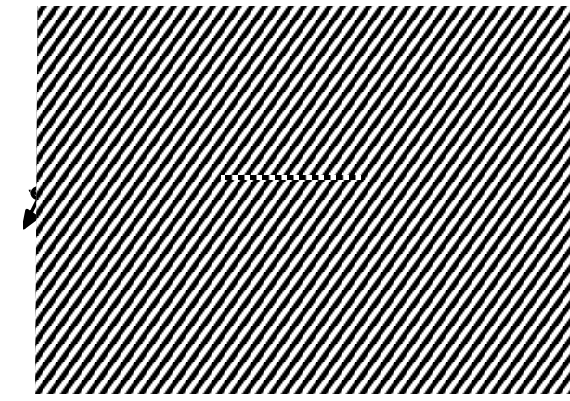

